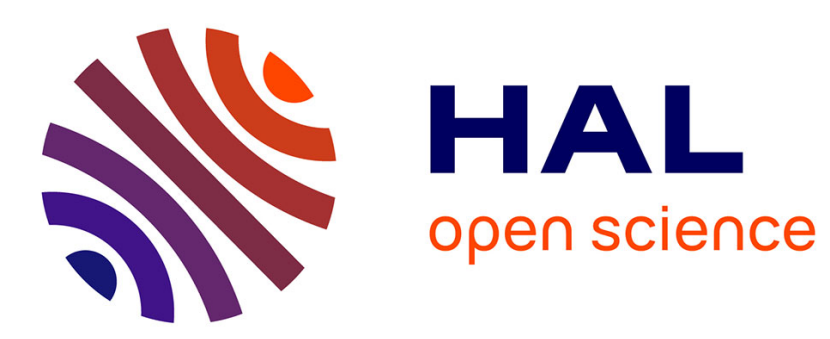

\title{
Physicians' balance billing, supplemental insurance and access to health care
}

\author{
Izabela Jelovac
}

\section{To cite this version:}

Izabela Jelovac. Physicians' balance billing, supplemental insurance and access to health care. 2013. halshs-00787602

\section{HAL Id: halshs-00787602 \\ https://shs.hal.science/halshs-00787602}

Preprint submitted on 12 Feb 2013

HAL is a multi-disciplinary open access archive for the deposit and dissemination of scientific research documents, whether they are published or not. The documents may come from teaching and research institutions in France or abroad, or from public or private research centers.
L'archive ouverte pluridisciplinaire HAL, est destinée au dépôt et à la diffusion de documents scientifiques de niveau recherche, publiés ou non, émanant des établissements d'enseignement et de recherche français ou étrangers, des laboratoires publics ou privés. 
Physicians' balance billing, supplemental insurance and access to health care

Izabela Jelovac

February 2013 


\section{GATE Groupe d'Analyse et de Théorie Économique Lyon-St Étienne}

93, chemin des Mouilles 69130 Ecully - France

Tel. +33(0)4 72866060

Fax $+33(0) 472866090$

6, rue Basse des Rives 42023 Saint-Etienne cedex 02 - France

Tel. +33 (0)4 77421960

Fax. +33 (0)4 77421950

Messagerie électronique / Email : gate@gate.cnrs.fr

Téléchargement / Download : http://www.gate.cnrs.fr - Publications / Working Papers 


\title{
Physicians' balance billing, supplemental insurance and access to health care
}

\author{
Izabela JELOVAC ${ }^{*}$
}

February 11, 2013

\begin{abstract}
Some countries allow physicians to balance bill patients, that is, to bill a fee above the one that is negotiated with, and reimbursed by the health authorities. Balance billing is known for restricting access to physicians' services while supplemental insurance against balance billing amounts is supposed to alleviate the access problem. This paper analyzes in a theoretical setting the consequences of balance billing on the fees setting and on the inequality of access among the users of physicians' services. It also shows that supplemental insurance against the expenses associated with balance billing, rather than alleviating the access problem, increases it.

Key-Words: Physicians' fees, balance billing, supplemental insurance.

JEL Classification: I13, I14, J33.
\end{abstract}

\footnotetext{
* University of Lyon, Lyon, F-69007, France; CNRS, GATE Lyon Saint-Etienne, Ecully, F-69130, France. E-mail: jelovac@gate.cnrs.fr

Funding from Chaire Santé Dauphine is acknowledged.
} 


\section{$1 \quad$ Introduction}

In many countries, the level of the physicians' basis fee results from a negotiation between a health authority, representatives of medical doctors and sometimes representatives of health services users as well. In a few countries, some physicians are allowed to bill an extra fee on top of the basis fee. This practice is known as balance billing. The public health insurer reimburses the physicians' basis fee only, or a fraction thereof. The patients pay the extra fee, unless privately insured against it. This paper aims at analyzing the consequences of both balance billing (BB, henceforth) and the insurance against the expenses generated by $\mathrm{BB}$, on the fees setting and on the resulting access inequalities among the users of physicians' services.

Few countries allow physicians to bill patients a fee above the one that is reimbursed by the health authorities. In France, BB has been allowed since 1980 to slow down the growing health care expenditures by avoiding increases in the basis fee. BB has been unregulated in France until 1990, and then restricted to physicians, mainly specialists, with a specific career pattern. According to the Caisse Nationale de l'Assurance Maladie (2011), the BB amounts have more than doubled between 1990 and 2010. On average, it amounts to $12 \%$ of physicians' total revenue (17\% for specialists in general, 32\% for surgeons). Private insurers in France can offer supplemental policies to reimburse partially or totally the expenses generated by physicians' balance billing. $94 \%$ have a private supplemental health insurance in France, but only $40 \%$ are insured against BB expenses. Private insurance against BB expenses is restricted in Belgium by a strict regulation of the health insurance sector. In the US, additional prices are now limited to about $10 \%$ of the Medicare fee while a new law in France restricts the BB amounts to $150 \%$ of the basis fee since October 2012.

It is generally recognized that BB increases inequalities because it restricts access. Our approach specifically addresses the issue of access to physicians' services. Buchmueller et al (2004) explain that equity and access to physicians' services are definitely an issue in France where balance billing and unregulated supplemental insurance coexist. In particular, a study by Buchmueller and Couffinhal (2004) found 
that, controlling for socioeconomic and demographic characteristics and detailed measures of health status, adults with private insurance were $86 \%$ more likely to visit a physician within a one month period than those without complementary coverage. This difference is comparable to differences between insured and uninsured adults in the US, where the insured/uninsured differential in out-of-pocket costs is much greater. Després et al. (2011) provide empirical evidence that people without supplemental insurance forego treatments that are not well reimbursed; they forego treatments twice as much as privately insured people. Després et al (2011) highlight that foregoing treatment is significantly more frequent where BB amounts are higher.

Rather than focusing on access, the existing theoretical papers on fees formation under balance billing analyze the important quality issue. Glazer and McGuire (1993) consider that the extra fee is a simple transfer from patients to physicians and its level is therefore irrelevant from the efficiency point of view. They do not recognize that some patients might stop seeking physicians' services because those are too expensive. The same happens in Kifmann and Scheuer (2006) because of another assumption: Physicians have information about the patients willingness to pay and they are therefore able to perfectly price discriminate among them, allowing all patients to access their services. We depart from these papers by implicitly assuming asymmetric information about patients' ability to pay, letting physicians to balance bill all patients with the same fee.

Intuitively, we expect that balance billing results in lower basis fees since physicians can compensate a lower basis fee with a higher extra fee. However, this very effect eventually results in higher basis fees. Indeed, the health authority anticipates the following effects: the physician's best reply to a higher basis fee is the setting of a lower extra fee, which is the price paid by the patients unless privately insured. This logically results in a higher demand for medical visits. Therefore, the trade-off faced by the health authority is the resulting higher consumers surplus against lower public expenses, provided physicians are granted a given level of revenue. When balance billing is not allowed, such a positive effect of the basis fee on the consumers surplus is absent since patients pay the same (say zero), whatever the level of the basis fee. The trade-off 
vanishes as the health authority only aims at reducing lower public expenses for paying the basis fees. Therefore, allowing balance billing need not lead to lower basis fees and to lower public expenses. Moreover, balance billing always increases inequality in access to physicians' services trivially because patients with the lowest revenues cannot afford the extra fees.

Some of these effects are reinforced by the presence of private insurance when it is not regulated. The basis fee is lower when some patients are privately insured against the payment of the extra fee because its reimbursement only benefits the uninsured while it has to be disbursed for all. The physicians' best response to a lower basis fee is to increase the extra fee even more. This means that access to physicians' services is even more restricted for the non-privately insured and sometimes for the privately insured as well. We show that this can also occur when we allow physicians to price discriminate between the privately and the non-privately insured.

The paper is organized as follows. Section 2 describes the theoretical model used to analyze these issues. Section 3 presents and analyzes two polar cases: The 'Laissezfaire' case with no negotiated basis fee and the fully regulated case with no balance billing. Section 4 then combines the regulator's setting of a basis fee with the possibility of balance billing. Section 5 extends to the existence of some privately insured individuals. Section 6 concludes.

\section{$2 \quad$ The model}

We model the relationship between a representative physician, a continuum of individuals of mass 1 and a regulator. Individuals are characterized by income $I$, uniformly distributed upon support $[0,1]$. They consume $y$ units of a numeraire good and $x=\{0,1\}$ visit to the physician. We assume that individual decisions concerning medical

insurance are done previously and that their health has suffered a negative shock. ${ }^{1}$ The consumers' problem is therefore as follows:

\footnotetext{
${ }^{1}$ The take up of private supplemental insurance is explicitly modeled in Section 5 (Appendix 3).
} 


$$
\operatorname{Max}_{x, y} y+x . V-L . \quad \text { s.t. }\left\{\begin{array}{c}
y+x . P \leq I \\
y \geq 0 \\
x=\{0,1\}
\end{array}\right.
$$

where $L$ represents the health loss suffered by the individuals; $V$ is the value to patients of a visit to the doctor. We assume $V>1$, to abstract from any moral hazard consideration and focus on the well-documented access issue. $P$ is the part of the physician's fee to be paid by the patient. Simplifying, we can write their utility as:

$$
U=\left\{\begin{array}{cc}
I-L+V-P & \text { if } x=1 \\
I-L & \text { if } x=0
\end{array}\right.
$$

and their decision resulting from their utility maximization as:

$$
x=\left\{\begin{array}{cc}
1 & \text { if } I \geq P \text { and } V \geq P \\
0 & \text { otherwise }
\end{array}\right.
$$

Therefore, the physician's demand and the consumers' surplus are, respectively: ${ }^{2}$

$$
D(P)=1-P, \quad \text { and } \quad C S=(V-P) \cdot(1-P), \quad \text { provided } V \geq P \text {. }
$$

The representative physician aims at maximizing his net revenue: $\Pi=(P+R-$ $c)(1-P)$, where $R$ is the basis fee, $P$ is the extra fee (consumers' price) and $c$ is a constant marginal cost, with $c<1$. We discard physicians' behaviors related to altruism, professional duty or paternalism.

The public expenses related to paying the physician the basis fee are $P E=R . D(P)$ $=R .(1-P)$. We assume that the regulator aims at maximizing the consumers' surplus net of public expenses, $S=C S-P E$.

In what follows, we analyze three cases on top of the laissez-faire case, to ultimately compare them with each other. First, we consider that the regulator decides on the level of the physician's basis fee, without allowing the latter to charge an extra fee to his patient. In that case, there is no room for supplemental insurance. In the second case, we allow the physician to balance bill while supplemental insurance is ruled out. Third,

\footnotetext{
${ }^{2}$ We only consider the part of the consumers' surplus that is directly related to the visit to the physician.
} 
the physician can balance bill and a proportion $\lambda$ of patients is privately insured against disbursing an extra bill.

To guarantee interior solutions, we also assume that $V<2+c$.

\section{Benchmark: Two polar cases}

The first is the pure market solution with neither public universal insurance nor private supplemental insurance. The physician decides upon his fee $P$ so as to maximize his net revenue:

$$
\Pi=(P-c) \cdot D(P)=(P-c) \cdot(1-P)
$$

The solution fee and the corresponding demand, physician's net revenue and consumers surplus are, respectively:

$$
\begin{aligned}
& P_{L F}=\frac{1+c}{2} ; \quad D_{L F}=\frac{1-c}{2} ; \quad \Pi_{L F}=\left(\frac{1-c}{2}\right)^{2} ; \\
& S_{L F}=C S_{L F}=\left(\frac{1-c}{2}\right) \cdot\left(V-\frac{1+c}{2}\right)
\end{aligned}
$$

Only individuals with an income above $P_{L F}$ can afford a visit to the physician.

In the second polar case, the patients are fully insured: the health authority reimburses the basis fee and no extra fee can be billed $(P=0)$. Therefore, all patients are always better off with a visit to their physician and their utility from this visit is $V$, no matter what their income level is. No inequality appears here other than the direct income-related one. The resulting physician's revenue, the consumers' surplus and the public expenses are, respectively:

$$
\Pi=R-c ; \quad C S=V ; \quad P E=R .
$$

Anticipating this situation, the basis fee $R$ is the solution to the following maximization problem for the regulator:

$$
\operatorname{Max}_{R} \quad V-R \quad \text { st } \quad R-c \geq \Pi_{L F},
$$


where the reservation revenue $\Pi_{L F}$ is previously defined as the solution to the laissez-faire case. Notice that we implicitly assume full negotiation power on the regulator's side. The solution is therefore:

$$
R_{F R}=\left(\frac{1+c}{2}\right)^{2}
$$

The resulting payoffs are the following:

$$
\Pi_{F R}=\left(\frac{1-c}{2}\right)^{2} ; \quad S_{F R}=V-\left(\frac{1+c}{2}\right)^{2}
$$

\section{$4 \quad$ Balance billing and no supplemental insurance}

In the present case, the physician is allowed to bill an extra fee to the patients, to maximize his net revenue:

$$
\Pi=(P+R-c) \cdot(1-P)
$$

The best reply of the physician to the setting of a basis fee in the previous stage is:

$$
P=\frac{1+c-R}{2}
$$

This extra fee is decreasing in the basis fee $R$. To decide the extra bill $P$, the physician trades off his revenue per patient against demand. When $R$ increases, the revenue per patient increases as well, other things being equal. Therefore, a higher $R$ allows the physician to focus more on demand when deciding the extra fee $P$. A lower $P$ is then set to grant a higher demand. The corresponding payoffs are the following, for both the physician and the regulator:

$$
\Pi=\left(\frac{1-c+R}{2}\right)^{2} ; \quad S=\frac{1-c+R}{2}\left(V-\frac{1+c+R}{2}\right) .
$$

One step backwards, we solve for the basis physician's fee in this case, which is the solution to the following regulator's problem:

$$
\operatorname{Max}_{R} \quad S=\frac{1-c+R}{2}\left(V-\frac{1+c+R}{2}\right) \quad \text { s.t. } \Pi=\left(\frac{1-c+R}{2}\right)^{2} \geq \Pi_{L F} .
$$


The basis fee is therefore

$$
R_{B B}=V-1
$$

Comparing this fee with the one obtained under full reimbursement, we obtain the following result.

\section{Proposition 1}

The basis fee can be higher when balance billing is allowed than when it is not. Formally, using $\tilde{V}=1+\left(\frac{1+c}{2}\right)^{2}$ where $1<\tilde{V}<2+c$,

$$
\left\{\begin{array}{l}
R_{B B} \geq R_{F R} \Leftrightarrow V \geq \tilde{V} \\
R_{B B}<R_{F R} \Leftrightarrow \tilde{V}<\tilde{V}
\end{array}\right.
$$

The intuition behind this result is the following. On top of increasing the physician's revenue, the basis fee $R$ plays the role of limiting the extra fee $P$, paid directly by the patient. Therefore, the regulator needs not aim at the lowest $R$ since he trades off patients' surplus (the importance of which is increasing in the value $V$ ) against public expenses, even though the participation constraint of the representative physician would have been satisfied with a lower reimbursed basis fee. This effect was not present when balance billing was forbidden.

The table presented in Appendix 1 summarizes the solution to this case, together with the polar cases presented in the benchmark and the case allowing supplemental insurance, analyzed in the next section. This table helps establishing the following results.

\section{Proposition 2}

The fee $P$ is lower when balance billing is associated to a reimbursement, than under the laisser-faire situation. Formally, $P_{L F}>P_{B B}>P_{F R}=0$.

Therefore, reimbursement still improves access to physicians' services, even if not for everyone. 


\section{Proposition 3}

The public expenses can be higher when balance billing is allowed than when it is not, despite the lower demand for physician's services under balance billing. Physician's revenue is higher when balance billing is allowed while the consumer surplus net of public expenses decreases with balance billing.

Formally, $D_{B B}<D_{F R}, \Pi_{B B}>\Pi_{F R}, S_{B B}<S_{F R}$, and there exists $\hat{V}$ with $\tilde{V}<\hat{V}<2+c$, such that

$$
\left\{\begin{array}{l}
P E_{B B} \geq P E_{F R} \quad \Leftrightarrow \quad V \geq \hat{V} \\
P E_{B B}<P E_{F R} \Leftrightarrow V<\hat{V}
\end{array}\right.
$$

\section{Proof: See Appendix 2}

This means that balance billing does not always allow saving on public expenses dedicated to physicians' fees, contrary to the purpose of the 1980 law in France that allowed BB.

\section{$5 \quad$ Balance billing and supplemental insurance}

We now consider that potential patients can take up partial private insurance against the disbursement of the extra fee $P$. Against the periodic payment of a premium $q$, individuals disburse only a share $a$ of the fee $P$ in case of illness. We analyze this decision in Appendix 3 and show that the demand for private insurance, denoted $\lambda$, in this competitive market is independent on the endogenous variables of our model. Therefore, we can consider the stage concerning the representative physician's problem independently from the private insurance choice problem since the latter is independent of the physician's choice of $P$, at equilibrium.

A proportion $\lambda$ of the patients are privately insured and pay only $a P$ when sick. ${ }^{3}$ Their total demand for physicians' services is $\lambda .(1-a P)$. The remaining proportion of patients pay the extra fee in full and their problem is equivalent to the one under balance

\footnotetext{
${ }^{3}$ In what follows we use the notation $\lambda$ as such because its expression is based on an exogenous variable only (see Appendix 3).
} 
billing without supplemental insurance. Their demand is thus $(1-\lambda) \cdot(1-P)$ and the total demand faced by the physician is as follows:

$$
D(P)=\lambda \cdot(1-a P)+(1-\lambda) \cdot(1-P)=1-P+e P,
$$

where the term $e=(1-a) \lambda$ is used to illustrate the extent of private insurance. If the private insurance had no effect on the extra fee $P$, the total demand for physician's services would naturally depend positively on the extent of private insurance. This is the direct effect of private insurance.

The physician sets the extra fee to maximize his revenue:

$$
\Pi=(R+P-c) \cdot(1-P+e P) .
$$

The solution to this problem gives us the physician choice of $P$ as a best reply to the basis fee $R$ :

$$
P=\frac{1}{2}\left(\frac{1}{1-e}-(R-c)\right)
$$

This fee is increasing in the extent of private insurance, $e$. Therefore, for a given level of the basis fee, the access to physicians' services is more severely restricted for the uninsured when supplemental coverage applies. Also, as in the former case, it is decreasing in $R$. The corresponding demand and total physician's net revenue are as follows:

$$
D=\frac{1+(1-e)(R-c)}{2} ; \quad \Pi=\frac{1}{1-e}\left(\frac{1+(1-e)(R-c)}{2}\right)^{2}
$$

The demand is surprisingly enough decreasing in the extent of private insurance, $e$, while the total net revenue is increasing in it. The extent of private insurance influences the demand through two opposite effects. We already mentioned the first, direct effect: More insured individuals imply more visits to the doctors since more people are better reimbursed. However, this also increases the extra fee, decreasing the demand from those who are not privately insured. The second effect dominates the first one here. 
Notice that the physician's profits are always higher than in the laisser-faire situation, whatever the level of the basis fee $R$ :

$$
\Pi=\frac{1}{1-e}\left(\frac{1+(1-e)(R-c)}{2}\right)^{2}>\Pi_{L F}=\left(\frac{1-c}{2}\right)^{2}
$$

Therefore, one step backwards, the regulator's problem reduces to:

$$
\begin{gathered}
\operatorname{Max}_{R} S=\lambda(V-a P-R)(1-a P)+(1-\lambda)(V-P-R)(1-P) \\
\text { such that } P=\frac{1}{2}\left(\frac{1}{1-e}-(R-c)\right) .
\end{gathered}
$$

The solution basis fee is therefore:

$$
R_{S I}=V-1-\frac{e}{1-(1-a) e}\left\{2+a\left(V-c-\frac{2-e}{1-e}\right)\right\} \text {. }
$$

It is lower than in the absence of private supplemental insurance:

$$
R_{S I}<R_{B B}=V-1
$$

This means that the public fee reimbursement decreases when supplemental insurance and balance billing co-exist. The intuition for this lower public reimbursement of physician's services is that it now only benefits those who are not privately insured while it must be disbursed for all.

Given this level of basis fee $R_{S I}$, the physician's best response in terms of extra fee is therefore:

$$
P_{S I}=\frac{2+e-(1-e)(V-c)}{2(1-e+a e)} .
$$

It is straightforward to show that this extra fee is higher with private insurance $(e>0)$ than without it $(e=0)$. This means that access to physicians' services is even more restricted for the uninsured when supplemental insurance is available. There also exist some parameter configurations (high proportion of privately insured, $\lambda$, and low rate of 
supplemental coverage, $a$ ) under which even the privately insured have less access than in the absence of private supplemental insurance:

$$
a P_{S I}>P_{B B} \Leftrightarrow V-c>\frac{2(1-\lambda)+a \lambda}{(1-\lambda)+2 a \lambda} .
$$

To summarize the effects of supplemental private insurance in a market for physicians' services in which balance billing is permitted, the following result presents the overall comparison, based on the table in Appendix 1, between the present case with supplemental insurance and the one of the former section without supplemental insurance.

\section{Proposition 4}

The existence of a competitive market for private insurance against the risk of disbursing the totality of an extra fee to physicians, results in lower basis fees, higher extra fees, a lower demand for physicians' services, i.e. a more restricted access for the non-privately insured and sometimes for the privately insured as well, and lower public expenses.

Formally, $R_{S I}<R_{B B}, P_{S I}>P_{B B}, D_{S I}<D_{B B}, P E_{S I}<P E_{B B}$ and

$$
a P_{S I}>P_{B B} \Leftrightarrow V-c>\frac{2(1-\lambda)+a \lambda}{(1-\lambda)+2 a \lambda} .
$$

Public expenses are lowered by the existence of private insurance because the publicly reimbursed fees are lower and so is the demand for public reimbursements, i.e. for physicians' services.

We close this section considering that the physician can price discriminate between the privately insured and the others. In this case, the fees are as follows: ${ }^{4}$

$$
P_{a}=\frac{1}{2}\left(\frac{1}{a}-(R-c)\right) ; \quad P_{1}=\frac{1}{2}(1-(R-c)) ; \quad R_{1 a}=\frac{(1-e) V+a e c-1}{1-e+a e} .
$$

\footnotetext{
${ }^{4}$ We use the subscript $a$ for the privately insured and the subscript 1 for the others.
} 
This price discrimination goes in favor of the non-privately insured. However, the overall comparison is not affected by this new possibility. The next proposition summarizes the comparison between these results and the former cases.

\section{Proposition 5}

When a competitive private insurance market coexists with the possibility to balance bill, and the physician can price discriminate between the privately insured and the others, the latter are better off than without discrimination but worse off than with no supplemental insurance at all. The privately insured are sometimes worse off as well when a market for supplemental insurance exists.

Formally, $R_{1 a}<R_{B B}, P_{B B}<P_{1}<P_{S I}$ and

$$
a P_{a}>P_{B B} \Leftrightarrow V-c>\frac{1+2 \lambda+a \lambda}{1-\lambda+a \lambda}
$$

\section{Conclusion}

We use a simple model to analyze the effects of (1) physicians' BB and (2) supplemental insurance against the disbursement of the totality of the BB amounts. Compared with a situation without $\mathrm{BB}$, we conclude that $\mathrm{BB}$ alone results in higher publicly reimbursed physicians' basis fees, increased public spending and more restricted access to physicians' services. The supplemental insurance only alleviates the effect on public expenses. Indeed, it decreases the public expenses because it decreases the basis fee, which actually reflects a lower protection of the privately uninsured. The extra fees paid by the privately uninsured increase, worsening even more their access to physicians' services. When many people are insured and the private coverage of the BB amount is low, the partial payments of the extra fees by the privately insured increase as well. So private insurance may end up worsening access for all in some cases. This can also occur when we allow physicians to price discriminate between the privately and the nonprivately insured.

All these effects are intuitive and likely to appear in more sophisticated models of physicians payments with BB. To add realism, these effects should be added to those 
resulting from competition between physicians and from the possible existence of moral hazard on the patients' side. The absence of competition between physicians in our model is still compatible with a situation where physicians have market power because of either high patients' switching costs, or a limited supply of physicians' services, or both. In turn, the absence of patients' moral hazard in our model can reflect a situation where the access issue (prices too high for some people) is actually more important than the moral hazard issue (prices too low for some other people). 


\section{References}

Buchmueller T.C., Couffinhal A., Grignon M. and Perronnin M. (2004). Access to physician services: does supplemental insurance matter? Evidence from France. Health Economics 13(7), 669-687.

Buchmueller T. C. and Couffinhal A. (2004), Private health insurance in France. OECD Health Working Papers, No. 12, OECD Publishing.

Caisse Nationale de l'Assurance Maladie (2011). Médecins exerçant en secteur 2: une progression continue des dépassements d'honoraires. 17 mai 2011.

http://www.ameli.fr/fileadmin/user_upload/documents/DP_medecins_en_secteur_ 2_-_vdef.pdf

Després C., Dourgnon P., Fantin R. and Jusot F. (2011). Giving up on health care for economic reasons: an econometric approach. Irdes, Questions d'économie de la santé n¹70, octobre. http://www.irdes.fr/EspaceRecherche/Qes2011.html\#n170

Glazer J. and McGuire T. (1993). Should physicians be permitted to 'balance bill' patients? Journal of Health Economics 11, 239-258.

Kifmann M. and Scheuer F. (2011). Balance billing: the patients' perspective. Health Economics Review 1:14.

Yaari M.E. (1987). The dual theory of choice under risk, Econometrica 55(1), 95-115. 


\section{Appendix 1 - Summary table}

\begin{tabular}{|c|c|c|c|}
\hline Laisser-faire & Full reimbursement & $\begin{array}{l}\text { BB, no supplemental } \\
\text { insurance }\end{array}$ & BB \& supplemental insurance \\
\hline$P_{L F}=\frac{1+c}{2}$ & $P_{F R}=0$ & $P_{B B}=1-\frac{V-c}{2}$ & $P_{S I}=\frac{2+e-(1-e)(V-c)}{2(1-e+a e)}$ \\
\hline$R_{L F}=0$ & $R_{F R}=\left(\frac{1+c}{2}\right)^{2}$ & $R_{B B}=V-1$ & $R_{S I}=V-1-\frac{e}{1-e+a e}\left\{2+a\left(V-c-\frac{2-e}{1-e}\right)\right\}$ \\
\hline$D_{L F}=\frac{1-c}{2}$ & $D_{F R}=1$ & $D_{B B}=\frac{V-c}{2}$ & $D_{S I}=\frac{(1-e)^{2}(V-c)-e(1-e-2 a)}{2(1-e+a e)}$ \\
\hline$\Pi_{L F}=\left(\frac{1-c}{2}\right)^{2}$ & $\Pi_{F R}=\left(\frac{1-c}{2}\right)^{2}$ & $\Pi_{B B}=\left(\frac{V-c}{2}\right)^{2}$ & $\Pi_{S I}=\frac{1}{1-e}\left(\frac{(1-e)^{2}(V-c)-e(1-e-2 a)}{2(1-e+a e)}\right)^{2}$ \\
\hline$S_{L F}=\left(\frac{1-c}{2}\right)\left(V-\frac{1+c}{2}\right)$ & $S_{F R}=V-\left(\frac{1+c}{2}\right)^{2}$ & $S_{B B}=\left(\frac{V-c}{2}\right)^{2}$ & $S_{S I}=S C_{S I}-P E_{S I}$ \\
\hline$S C_{L F}=\left(\frac{1-c}{2}\right)\left(V-\frac{1+c}{2}\right)$ & $S C_{F R}=V$ & $S C_{B B}=\left(V-1+\frac{V-c}{2}\right)\left(\frac{V-c}{2}\right)$ & $\begin{aligned} S C_{S I} & =\lambda\left(V-a P_{S I}\right)\left(1-a P_{S I}\right) \\
& +(1-\lambda)\left(V-P_{S I}\right)\left(1-P_{S I}\right)\end{aligned}$ \\
\hline$P E_{L F}=0$ & $P E_{F R}=\left(\frac{1+c}{2}\right)^{2}$ & $P E_{B B}=(V-1)\left(\frac{V-c}{2}\right)$ & $P E_{S I}=D_{S I} R_{S I}$ \\
\hline
\end{tabular}

\section{Appendix 2 - Proof of Proposition 3}

$D_{B B}<D_{F R}$ and $\Pi_{B B}>\Pi_{F R}$ come from direct comparisons using the table in Appendix 1.

Using the same table, we see that $P E_{B B}$ is increasing in $V$.

Evaluated at $V=\tilde{V}$, we have $P E_{F R}=\left(\frac{1+c}{2}\right)^{2}>P E_{B B}=\frac{(V-c)(V-1)}{2}$.

Evaluated at $V=2+c$, we have $P E_{F R}=\left(\frac{1+c}{2}\right)^{2}<P E_{B B}=\frac{(V-c)(V-1)}{2}$. 
Therefore, for $V>\hat{V}$ high enough, $P E_{B B}>P E_{F R}$.

A similar analytical argument is used to show that $S_{B B}<S_{F R}$ (available upon request from the author).

QED

\section{Appendix 3 - The demand for private insurance}

We use the dual theory formulation of expected utilities (see Yaari, 1987) to model individual choice of private insurance taking.

Let $\mu$ be the true probability that an individual gets sick and needs to disburse the extra fee $P$. Let $\alpha \mu$ be the individual perceived probability to get sick, with $\alpha>1$. There is a competitive insurance market offering partial coverage of the extra fee $P$ (the partial coverage being $(1-a) P$ ) against the payment of a premium denoted $q$. Individuals will therefore take up insurance if:

$$
I-q-\alpha \mu a P \geq I-\alpha \mu P \quad \Leftrightarrow \quad \mu \geq \frac{q}{\alpha(1-a) P} .
$$

Assuming that $\mu$ is uniformly distributed upon the support $[0,1]$, the demand for private insurance is therefore:

$$
\lambda=1-\mu=1-\frac{q}{\alpha(1-a) P} .
$$

We now turn to the equilibrium premium $q$ that prevails on a competitive private insurance market. This premium is such that profits of the insurance companies are zero:

$$
\int_{\frac{q}{\alpha(1-a) P}}^{1}(q-\mu(1-a) P)=q\left(1-\frac{q}{\alpha(1-a) P}\right)-\frac{(1-a) P}{2}\left(1-\frac{q}{\alpha(1-a) P}\right)\left(1+\frac{q}{\alpha(1-a) P}\right)=0 \Leftrightarrow q=\frac{\alpha(1-a) P}{2 \alpha-1} .
$$

Therefore, the demand for private insurance in this competitive market is independent from the endogenous variables of our model:

$$
\lambda=1-\frac{q}{\alpha(1-a) P}=1-\frac{1}{2 \alpha-1}=\frac{2(\alpha-1)}{2 \alpha-1} .
$$

